\title{
Spectroscopic studies of the quality of WCO (Waste Cooking Oil) fatty acid methyl esters
}

\author{
Arkadiusz Matwijczuk ${ }^{1, *}$, Grzegorz Zając ${ }^{2, * *}$, Dariusz $\mathrm{Karcz}^{3}$, Edyta Chruściel $^{1}$, Alicja \\ Matwijczuk $^{1}$, Magdalena Kachel-Jakubowska ${ }^{4}$, Bogusława Lapczyńska-Kordon ${ }^{6}$, and \\ Mariusz Gagoś ${ }^{4}$ \\ ${ }^{1}$ University of Life Sciences in Lublin, Department of Physics, Poland \\ ${ }^{2}$ University of Life Sciences in Lublin, Department of Power Engineering and Transportation, Poland \\ ${ }^{3}$ Krakow Technical University, Department of Analytical Chemistry (C1), Poland \\ ${ }^{4}$ University of Life Sciences in Lublin, Department of Machinery Exploitation and Management of \\ Production Processes, Poland \\ ${ }^{5}$ Maria Curie-Skłodowska University, Department of Cell Biology, Poland \\ ${ }^{6}$ Department of Mechanical Engineering and Agrophysics, Faculty of Production and Power \\ Engineering, University of Agriculture in Kraków
}

\begin{abstract}
Different kinds of biodiesel fuels become more and more attractive form of fuel due to their unique characteristics such as: biodegradability, replenishability, and what is more a very low level of toxicity in terms of using them as a fuel. The test on the quality of diesel fuel is becoming a very important issue mainly due to the fact that its high quality may play an important role in the process of commercialization and admitting it on the market. The most popular techniques among the wellknown are: molecular spectroscopy and molecular chromatography (especially the spectroscopy of the electron absorption and primarily the infrared spectroscopy (FTIR)).The issue presents a part of the results obtained with the use of spectroscopy of the electron absorption and in majority infrared spectroscopy FTIR selected for testing samples of the acid fats WCO (Waste Cooking Oil) types. The samples were obtained using laboratory methods from sunflower oil and additionally from waste animal fats delivered from slaughterhouses. Acid methyl esters were selected as references to present the samples. In order to facilitate the spectroscopic analysis, free glycerol, methanol, esters and methyl linolenic acid were measured.
\end{abstract}

\section{Introduction}

The massive expansion of internal combustion engines is associated from the outset with the use of primarily crude oil as an energy source. In almost one hundred years old history of generally understood automotive industry the only fuel hydrocarbon fractions were extracted from crude oil, which still remains the most important energy source. In this respect, it also has a very large impact on the global

*Corresponding author: arkadiusz.matwijczuk@up.lublin.pl, arekmatwijczuk@gmail.com

${ }^{* *}$ Corresponding author: grzegorz.zajac@up.lublin.pl 
political and economic situation. However, the modern world realized that global deposits of oil are largely reduced and the the ever-increasing consumption causes a serious ecological threat such as a greenhouse effect caused by $\mathrm{CO}_{2}$ gas. This fact has become a powerful driving force for many research programs around the world to search for alternative fuels which would partially or completely replace the conventional fossil fuels and cast little threat to the environment[1-4]. In this context, the fuel constituents derived from renewable sources such as bio fuels seem to play the most important role. Among the various types of bio fuels the biodiesel (most often defined as the fatty acid methyl esters (FAME)) is most attractive. It should be noted that the application of FAME either as fuel for compression engines or ignition or as a gas component considerably changes the properties which have been known so far. Significant differences in chemical structures of hydrocarbons present in diesel and FAME differentiate the behavior of these products and affect their handling, storage conditions as well as the engine compartment. Currently, practically every vegetable or animal fats can be used as a raw material for the production of various types of biodiesel. The most commonly manufactured raw materials are edible vegetable oils and rapeseed oils, soy, sunflower or even palm oil.

Those raw materials, referred to as the first generation, do not resolve major issues such as reduction of $\mathrm{CO}_{2}$ emission and may even increase problems on the food market [5-6]. Focusing attention on acquisition of raw materials seems to be the solution to this situation. II generation i. e. edible plant oils such as algae and microalgae [7], Jatropha [8] or used vegetable oil can be obtained from households or restaurants.

There are two main factors which prove that waste oil (WCO) is nowadays one of the most promising raw materials for the production of biodiesel [9-12], namely the wide availability of the raw material and the very low production cost. Due to the increasing consumption, the amount of waste oils is growing very quickly. For example, only in the United States about 10 million tons of the WCO is generated annually. This in turn requires environmentally friendly methods for WCO disposal and in this context the use of WCO as a raw material for biodiesel production is considered economically advantageous [13]. It has been estimated that the low cost of biodiesel production from WCO may help in overcoming the economical barriers. Currently the biodiesel production cost is $\sim 1.5$ times higher compared to that of conventional diesel, and only this fact speaks much for the opportunity to introduce biodiesel on a larger scale. It is estimated that more than $70 \%$ of the cost of biodiesel production is cost-per-acquisition of raw material [14-15]. It should be pointed out that the price of the WCO is 2-3 times lower compared to the price of crude vegetable oils, which can substantially lower the production costs of the same fuel in the form of biodiesel. Also, a significant reduction in the costs of waste disposal is an additional worth-mentioning advantage [16]. Due to the structural transformations taking place in frying oil over time [16], the chemical and physical properties of WCO oils differ from those of fresh oil. As a result of the frying temperature (approx. $190{ }^{\circ} \mathrm{C}$ ) as well as the presence of $\mathrm{O}_{2}$ and $\mathrm{H}_{2} \mathrm{O}$ from fried products, similar physical and chemical changes occur both in the food, and in oil medium used for frying. These changes can result in the formation of various compounds that often have very complex and unidentified structures, such as free fatty acids (FFA) [17-19]. The presence of solids together with significant quantities of $\mathrm{H}_{2} \mathrm{O}$ in the test products (those may come with fried products and are introduced during the washing) may also be problematic. Hence, the fact that the profile of fatty acids composition and the free fatty acids content in raw materials affect physicochemical properties of derived bio fuels is undisputable. 
The use of WCO for biodiesel production requires an appropriate technology with advanced pretreatment processes and selection of relevant transesterification reaction parameters. Various contaminants such as water, organic compounds and substances which cannot undergo saponification lower the transesterification yield and overall quality of biodiesel product. The quality of products obtained must be controlled by suitable analytical techniques, one of which is infrared FTIR spectroscopy [20-24].

The main purpose of current work is the application of infrared spectroscopy and FTIR-spectroscopic properties of WCO oils for assessing the suitability of the WCO for the production of biodiesel.

\section{Materials and Methods}

\subsection{Materials}

All fatty acid methyl esters tested were obtained from fresh oils using laboratory methods. All frying oils (WCO), waste animal fats and bio-commercial oils used for the experiments meet the requirements of EN 14214:2006 standard.

The following oil materials were used:

1. Refined sunflower oil underwent five cycles of frying potato French fries. Single cycle consisted of heating the oil up to the temperature of $180^{\circ} \mathrm{C}$ followed by an insertion of vegetable material.

2. Refined sunflower oil underwent five cycles of frying fish fingers. The production cycle was carried out in the same way as in 1.

3. Waste animal fats, were obtained from a slaughterhouse. They were melted down by their slow heating up to the temperature of $60^{\circ} \mathrm{C}$ (under greatly reduced pressure in order to prevent its degradation). Remains of poured, drained fat were centrifuged and decanted. The raw materials obtained were subjected to esterification in a lab reactor $(\mathrm{V}=1000 \mathrm{ml})$ and adjustable temperature stabilization.
The reaction time and mixing speed were based on the available literature [25-27]. In order to begin the trans-esterification reaction the experiments were carried out in temp. of $55^{\circ} \mathrm{C}$. After reaching the desired temperature all tested oil samples were treated by a catalytic mixture consisting of methanol and $\mathrm{NaOH}$. The reaction mixtures were stirred for $2 \mathrm{~h}$ using power agitator.

In order to completely separate the Glycerin and esters obtained, the mixture was subjected to $8 \mathrm{~h}$ long sedimentation process. The esters were then washed twice with hot water (at $80^{\circ} \mathrm{C}$ ) and dried to remove the remaining alcohol and catalyst used.

Then, each of the selected studies of esters was tested with regard to the peroxide number (LN) [PN-ISO 3960], number of acid (LK) [PN-ISO 660] and composition of higher fatty acids that are marked by gas chromatography. The gas chromatography with nitrogen has been used as the carrier gas, packed column (2.5 $\mathrm{m}$ with stationary phase PEGA, which consisted of polyethylene glycol adipate embedded GAS medium-chromium-Q) and a flame ionization detector.

\subsection{Methods}

Spectroscopic methods. Electronic absorption spectra were recorded at $23^{\circ} \mathrm{C}$ on double-beam UV-Vis spectrophotometer Cary 300 Bio (Varian, USA) equipped with a thermostated cuvette holder with a $6 \times 6$ multicell Peltier block. The temperature was controlled with a thermocouple probe (Cary Series II, Varian, USA) placed directly in the quartz cuvette. The spectra were recorded from 200 to $600 \mathrm{~nm}$.

The measurements of ATR-FTIR background-corrected spectra were carried out in solvents using a HATR Ge trough ( $45^{\circ}$ cut, yielding 10 internal reflections) crystal plate for liquids and were recorded with a 670-IR spectrometer (Varian, USA). Typically, 25 scans were collected, Fouriertransformed, and averaged for each measurement. The IR absorption spectra at 
a resolution of one data point per $1 \mathrm{~cm}-1$ were obtained in the region between 4000 and $400 \mathrm{~cm}-1$. The instrument was purged with argon for $40 \mathrm{~min}$ before and then during the measurements. The Ge crystal was cleaned with ultra-pure organic solvents (Sigma-Aldrich Co.). All experiments were carried out at $20^{\circ} \mathrm{C}$.

\section{Results and discussion}

Infrared spectrometry (FTIR) is a commonly used tool for analysis of the carbonyl group-containing compounds and for determination of the petroleum products. Its use for determination of the FAME content is based on the fact that the carbonyl $\mathrm{C}=\mathrm{O}$ vibration, which usually occurs at approximately $1700-1800 \mathrm{~cm}^{-1}$ is practically negligible in hydrocarbon fraction, while in case of FAME it is highly intense. It is well-known that esters give highly specific and strong absorption bands caused by vibrations of their $\mathrm{C}=\mathrm{O}$ and $\mathrm{C}-\mathrm{O}$ valence bonds.

The absorption band of the carbonyl group $\mathrm{C}=\mathrm{O}$ in saturated aliphatic esters usually appears at $1735-1750 \mathrm{~cm}^{-1}$. The aryl and $\alpha, \beta$-Unsaturated structure may cause slight shift of this band towards a shorter wavenumber values (i. e. $1715-1730 \mathrm{~cm}^{-}$ $\left.{ }^{1}\right)[28]$. The C-O stretching vibration emerges within a much broader range $\left(1100-1300 \mathrm{~cm}^{-1}\right)$, and is also observed in the spectra of other organic compounds such as carboxylic acids, ethers, or alcohols. Methyl esters belonging to the long-chain fatty acids often give rise to absorption maxima at approximately 1250 , 1205 , and $1175 \mathrm{~cm}^{-1}$ [29]. In case of FAME the most characteristic band has its maximum at approximately $1175 \mathrm{~cm}^{-1}[30]$.

Other characteristic of a hydrocarbon chain bands which occur in EMKT and ON are:

-methyl $\left(-\mathrm{CH}_{3}\right)$ and methylene $\left(-\mathrm{CH}_{2}-\right)$ groups $\mathrm{C}-\mathrm{H}$ stretching vibrations (both symmetrical and non-symmetrical), present at 2870 and $2965 \mathrm{~cm}^{-1}$ (former), and 2925, and $2850 \mathrm{~cm}^{-1}$ (latter)[31].
- bending vibrations of the $\mathrm{C}-\mathrm{H}$ bond: in methyl group present at $1375,1450 \mathrm{~cm}^{-1}$ (and $1438 \mathrm{~cm}^{-1}$ in compounds containing carbonyl group); in methylene group at 1465 (scissoring vibration), and $721 \mathrm{~cm}^{-1}$ (rocking vibrations)[32].

Interestingly, in the spectra of hydrocarbon fraction of diesel within the range of $1700-1800 \mathrm{~cm}^{-1}$ another characteristic band is present, while it is absent in the FAME spectrum. This suggests the presence of various oxidation products (aldehydes, ketones, carboxylic acids) or various oxidation inhibitors, for example -mediated inflammatory diseases. In addition, poor absorption of some in the vibrations of the maximum of approx. 1750 $\mathrm{cm}^{-1}$ can be attributed to the presence of small amounts (within 1\%) (that is, polymers with carbonyl groups)[33].

Although the formation of such carbonyl compounds is unlikely in highquality fuels, their presence may cause difficulties in the determination of FAME content. It should be noted, that despite those difficulties the band between 1750$1740 \mathrm{~cm}^{-1}$ is considered as optimal for the IR-based identification and quantitative analysis of FAME in medium oil fractions and lubricating oils[34].

Figure 1 shows the selected electron absorption spectra of the methyl esters from sunflower oil after frying French fries (black line) and fish (dashed line) and the spectrum of the selected commercial esters, dissolved in methanol (grey line).

The absorption maxima at approximately $270 \mathrm{~nm}$, for all samples of oils selected for tests $(279 \mathrm{~nm}$ for the methyl esters of rapeseed oil after frying French fries or fish and $281 \mathrm{~nm}$ for commercial esters) clearly indicate the origin of the band as the $n \rightarrow \pi^{*}$ electronic transition within the carbonyl group $(\mathrm{C}=\mathrm{O})[35-38]$.

In case of commercial esters a very broad absorption set of bands is easily noticed $(360$ - $510 \mathrm{~nm})$, which is not observed in the spectra of sunflower oil esters (after frying French fries and fish). 
This region of the spectrum may be characteristic either of various fuel additives e.g. biocides (synthetic or natural) or pollutants. Studies carried out on other esters (not shown) revealed spectral features similar to those presented in Fig. 1.

The FTIR spectra of the investigated esters are given in Fig. 2. The samples were dissolved in appropriate organic solvent and dispersed at the surface of $\mathrm{ZnSe}$ crystal and then the solvent evaporated in an atmosphere of inert gas $\left(\mathrm{N}_{2}\right)$.

The samples of sunflower oils after frying both French fries and fish have the characteristic maxima at about $1744 \mathrm{~cm}^{-1}$ $\left(1743 \mathrm{~cm}^{-1}\right.$ for the methyl esters of rapeseed oil) originating from carbonyl $\mathrm{C}=\mathrm{O}$ for stretch.

The spectrum of methyl esters from oil after frying French fries compared to that of esters from oil after frying fish (Fig. 2, top) shows a remarkable difference in the band shapes within the range of $1770-1670 \mathrm{~cm}^{-1}$. In particular, a clear decrease in the intensity of band at $1744 \mathrm{~cm}^{-1}$ is observed, most likely as a result of the formation of strong hydrogen bonding.

The band with the maximum at 1715 $\mathrm{cm}^{-1}$ neither is observed in the spectrum of commercial B100 nor in the spectra of the methyl esters of sunflower oil, clearly indicates a lack of ability to create this type of hydrogen bridges.

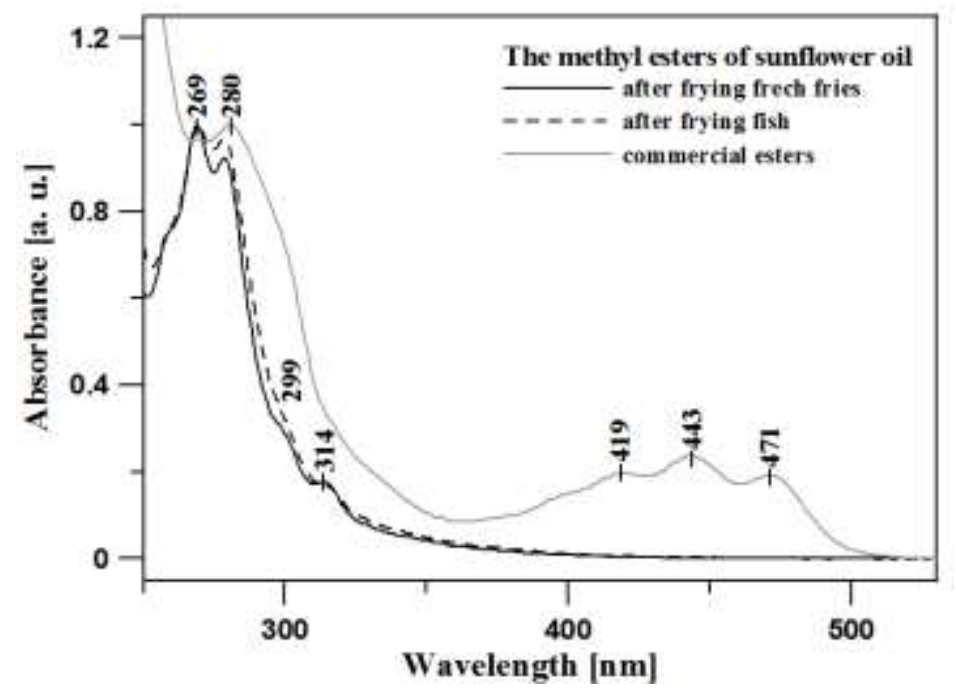

Fig. 1.Electronic absorption spectra of the methyl esters from sunflower oil after frying French fries (black line) and after frying fish (dashed black line) and esters commercial-B100 (grey line), dissolved in methanol (Mt-OH). 


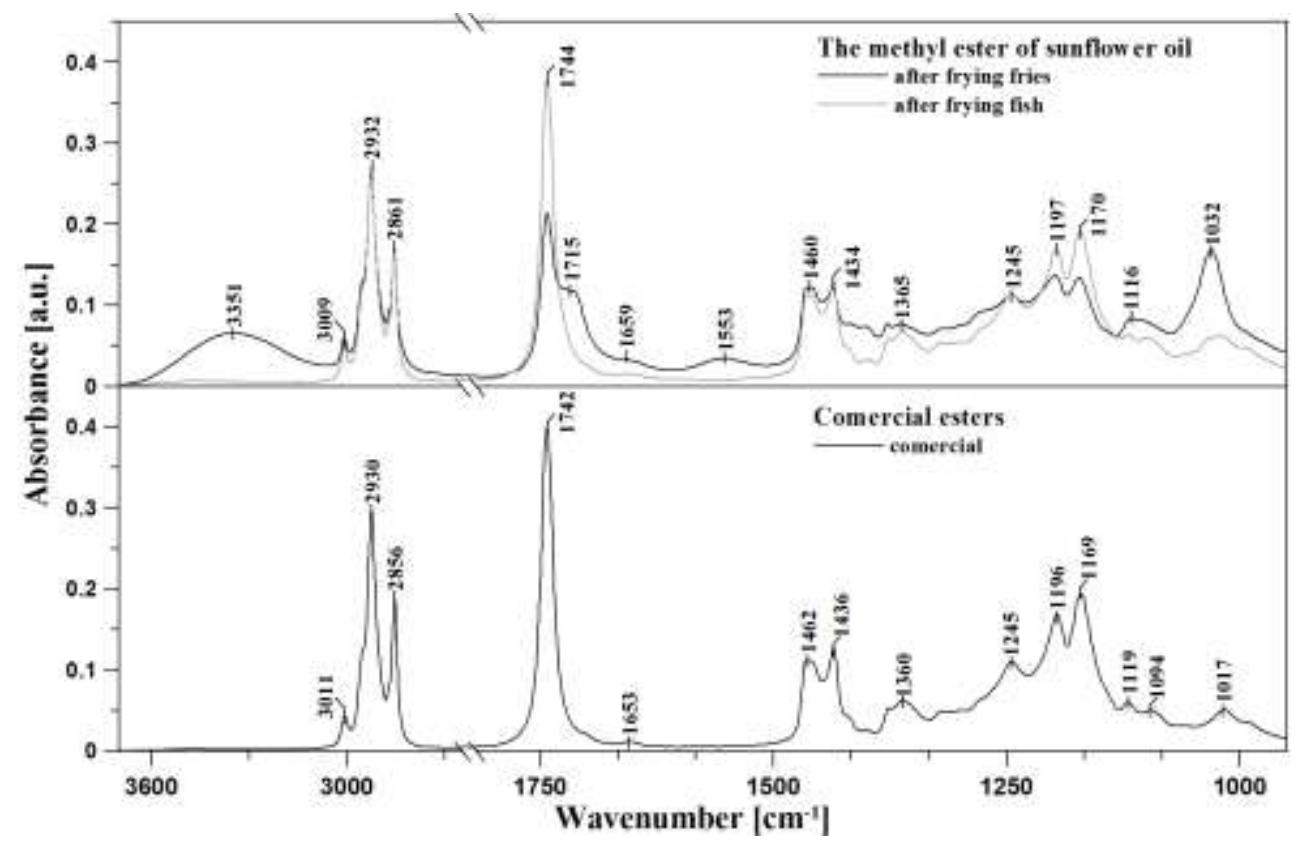

Fig. 2. ATR-FTIR absorption spectra of esters from sunflower oil after frying French fries (solid black line) and after frying fish (dashed black line) (top) and of commercial esters-B100, (bottom). All samples were dissolved in Mt-OH.

With the decrease in intensity of the band at $1744 \mathrm{~cm}^{-1}$ and the respective intensity increase of the band at $1715 \mathrm{~cm}^{-1}$ a simultaneous increase in intensity of the band at $1032 \mathrm{~cm}^{-1}$ associated with the $\mathrm{C}-\mathrm{O}$ stretching vibrations is observed. This band is also clearly visible in the spectra of methyl esters from oil after frying French fries and fish, while in the spectrum of commercial esters it is least intensive, which is most likely associated with the greatest intensity of carbonyl $\mathrm{C}=\mathrm{O}$ vibration in this spectrum. Bands in the area of 1100$1300 \mathrm{~cm}^{-1}$ also originate from C-O stretching, but only minimal differences are observed in this region between all spectra[34]. These bands together with a decreasing trend of hydrogen bonding between groups of $\mathrm{C}=\mathrm{O} \quad \mathrm{H}-\mathrm{O}-\mathrm{H}$ show small but noticeable increase in their intensity.
A similar trend is also observed in the spectrum of commercial esters. Interestingly, the area between 3680-3070 $\mathrm{cm}^{-1}$, with a broad band showing the maximum at approximately $3351 \mathrm{~cm}^{-1}$ results from the presence of a high content of methanol and a significant amount of $\mathrm{H}_{2} \mathrm{O}$ in the tested samples of esters[39]. This effect may also depend on whether the esters were used in frying French fries or fish. The studies have also revealed a glycerol content in the samples tested. the sample of commercial esters contains the lowest amount of glycerol. Analogical observation was made for methanol and methyl ester of linolenic acid content, which presence in the test esters is very well correlated with changes in the intensity of the bands at $3351 \mathrm{~cm}^{-1}$ [40-41]. An increased concentration of these compounds results in a significant decrease in intensities of these bands 
Table 1. Positioning of FTIR absorption maxima with assignment of appropriate vibrations in bio fuels tested (for the methyl esters of sunflower oil after frying French fries, fish and for commercial esters-B100 recorded within the range of $3700-900 \mathrm{~cm}^{-1}$.)

\begin{tabular}{|c|c|c|c|}
\hline \multicolumn{3}{|l|}{ FTIR } & \multirow{3}{*}{ Type and origin of vibrations } \\
\hline Positio & & & \\
\hline \multicolumn{2}{|c|}{ Esters of sunflower oil } & $\underline{B 100}$ & \\
\hline $3351 \mathrm{w}$ & 3351st & - & $v(\mathrm{O}-\mathrm{H})$ in $\mathrm{H}_{2} \mathrm{O}$ \\
\hline 3009 & 3009 & 3011 & $v(\mathrm{C}-\mathrm{H})$ \\
\hline 2932 & 2932 & 2920 & $\begin{array}{l}\mathrm{CH}_{2, \text { s+as, }} \mathrm{CH}_{3, \text { s+as aliphatic group }} \\
\text { of triglycerides }\end{array}$ \\
\hline 2861 & 2861 & 2856 & \\
\hline $1744 s t$ & $1744 w$ & $1742 \mathrm{~s}$ & $C-O$ - \\
\hline 1715 & - & - & $\mathrm{C}=\mathrm{U}$ group of Ester \\
\hline 1659 & 1659 & 1653 & $v(\mathrm{C}=\mathrm{C})$ \\
\hline 1553 & 1553 & - & $v(\mathrm{C}=\mathrm{C})_{\mathrm{s}}$ \\
\hline 1460 & 1460 & 1462 & $-\mathrm{C}-\mathrm{H}$ (in $\mathrm{CH}_{2}$ ) bending \\
\hline 1434 & 1434 & 1436 & $=C-H($ cis-) hendino \\
\hline 1417 & 1417 & 1418 & $=\mathrm{C}-\mathrm{H}\left(\mathrm{cls}^{-}\right)$benaing \\
\hline $1404 \mathrm{~m}$ & $1404 \mathrm{~m}$ & $1403 \mathrm{~m}$ & $v(=\mathrm{C}-\mathrm{H}(c i s-))$ \\
\hline 1376 & 1376 & 1377 & $-\mathrm{C}-\mathrm{H}_{\mathrm{s}}\left(\right.$ in $\left.\mathrm{CH}_{3}\right)$ \\
\hline 1365 & 1365 & 1360 & $-\mathrm{C}-\mathrm{H}_{\mathrm{s}}\left(\mathrm{CH}_{3}\right)$ bending \\
\hline 1317 & 1317 & 1319 & $\delta(\mathrm{CH})$ \\
\hline $1277 \mathrm{st}$ & $1277 \mathrm{st}$ & $1276 \mathrm{~m}$ & $\delta\left(\mathrm{CH}_{2}\right)$ \\
\hline 1245 & 1245 & 1245 & -C-O stretching \\
\hline 1197 & 1197 & 1169 & or $-\mathrm{O}-\mathrm{CH}_{2}-\mathrm{C}$ \\
\hline 1170 & 1170 & 1194 & $-\mathrm{C}-\mathrm{O}$ \\
\hline 1116 & 1116 & 1119 & \\
\hline 1132 & 1132 & 1117 & $v(\mathrm{C}-\mathrm{C})$ \\
\hline $914 \mathrm{~m}$ & $914 \mathrm{~m}$ & $910 \mathrm{~m}$ & $-\mathrm{OH}$ \\
\hline 860 & 860 & 859 & $v(\mathrm{C}-\mathrm{O}-\mathrm{C})_{\mathrm{s}}$ \\
\hline 839 st & 839st & $840 \mathrm{w}$ & $v(\mathrm{C}-\mathrm{O}-\mathrm{C})_{\mathrm{s}}$ or $v(\mathrm{C}-\mathrm{C})$ \\
\hline 721 & 721 & 722 & $-\mathrm{CH}_{2}$ - rocking \\
\hline
\end{tabular}

$v-$ stretching vibrations, $\delta$ - bending vibrations, $\mathrm{s}-$ symmetrical, as - asymmetrical, st - strong, ${ }^{*}$ denotes frequencies that may originate from the solvent used

\section{Conclusions}

This study presents the application of infrared spectroscopy and FTIR as a tool for analysis of the quality of the selected fatty acid-methyl esters as potential biodiesel components. The experiments primarily focused on the methyl esters obtained from waste oils WCO. The results obtained were compared with the spectra of commercial esters (B100) and comply to commercial standards EN 14214.

When using both spectroscopies: UV spectroscopy as well as FTIR infrared 
spectroscopy, key areas have been examined. The essence of the examination was to determine suitability of the information of the spectral test on the WCO ester type in order to apply them as a bio fuel.

It has been proved that the analysis of key areas in the UV-Vis and FTIR spectra of the selected waste oils may serve as an inexpensive source of information on the composition of these oils and their suitability as raw materials for biodiesel production.

\section{References}

1. [1] Group, U. N. E. P. B. W Management, UNEP/Earthprint, 2009.

2. [2] X. Wang, M.K. Lim, Y. Ouyang Energ. Econ. (2017)

3. [3] H.V. Lee, J.C. Juan, T.Y. Yun Hin, H.C. Ong Energies 9, 611 (2016)

4. [4] Z. Bakhtiyari, M. Yazdanpanah, M. Forouzani, N. Kazemi RENEW SUST ENERG REV 69, 341-349 (2017)

5. [5] A. Guldhe, B. Singh, N. Renuka, P. Singh, R. Misra, F. Bux Springer, 2017, pp. 47-62.

6. [6] D.S. Khang, R.R. Tan, O.M. Uy, M.A.B. Promentilla, P.D. Tuan, N. Abe, L.F. Razon RESOUR CONSERV RECY 119, 12-23 (2017)

7. [7] A. Klok, P. Lamers, D. Martens, R. Draaisma, R. Wijffels Trends Biotechnol. 32, 521-528 (2014)

8. [8] H. Ong, A. Silitonga, H. Masjuki, T. Mahlia, W. Chong, M. Boosroh Energy Convers. Manage. 73, 245-255 (2013)

9. [9] A.N. Phan, T.M. Phan Fuel 87, 3490-3496 (2008)

10. [10] R. Shan, C.Lv.P. Zhao, H. Yuan, J. Yao Energy Convers. Manage. 127, 273-283 (2016)

11. [11] Y.M. Isa, E.T. Ganda RENEW SUST ENERG REV 81, 69-75 (2018)

12. [12] T. Maneerung, S. Kawi, Y. Dai, C.H. Wang Energy Convers. Manage. 123, 487-497 (2016)
13. [13] S. Jose Springer, 2017, pp. 281313.

14. [14] J. Sakulsuraekkapong, R. Pairintra, S. Thepa ENERG SOURCE PART B 1-6 (2017)

15. [15] H.H. Mardhiah, H.C. Ong, H. Masjuki, S. Lim, H. Lee RENEW SUST ENERG REV 67, 1225-1236 (2017)

16. [16] W. Sawaengsak, T. Silalertruksa, A. Bangviwat, S.H. Gheewala ENERGY SUSTAIN DEV 18, 67-74 (2014)

17. [17] A. Sankoda, N. Harada, K. Iwasaki, S. Yamane, Y. Murata, K. Shibue, Y. Thewjitcharoen, K. Suzuki, T. Harada, Y. Kanemaru Endocrinology 158, 1172-1180 (2017)

18. [18] J. Sebastian, C. Muraleedharan, A. Santhiagu Cogent Engineering 3, 1178370 (2016)

19. [19] C.H. Tan, A.A. Ariffin, H.M. Ghazali,C.P. Tan, A. Kuntom, A.C.Y. Choo J Food Sci Technol 54, 17571764 (2017)

20. [20] B. Elzey, D. Pollard, S.O. Fakayode Food Control 68, 303-309 (2016)

21. [21] N. Cebi, M.T. Yilmaz, O. Sagdic, H. Yuce, E. Yelboga Food Chem. 225, 188-196 (2017)

22. [22] A. Hirri, M. Bassbasi, S Platikanov, R. Tauler, A. Oussama Food Anal Methods 9, 974-981 (2016)

23. [23] F. van de Voort, M. TavassoliKafrani, J. Curtis Anal. Chim. Acta 918, 1-7 (2016)

24. [24] A. Dominguez-Vidal, J. Pantojade la Rosa, L. Cuadros-Rodríguez, M.J. Ayora-Cañada Food Chem. 190, 122-127 (2016)

25. [25] A. Ramadhas, S. Jayaraj, C. Muraleedharan Renew Energy 29, 727-742 (2004)

26. [26] C. Sheinbaum, M.V. Balam, G. Robles, S. Lelo de Larrea, R. Mendoza Waste Manag. Res. 33, 730739 (2015)

27. [27] M. Szmigielski, W. Piekarski, D. Andrejko, B. Slaska-Grzywna, A. 
Maslowski, G. Zajac, A. Sagan, T. Jaskiewicz, I. Rachanczyk Przem Chem 93, 649-651 (2014)

28. [28] H. Omidvarborna, A. Kumar, D.S. Kim Sci. Total Environ. 544, 450-459 (2016)

29. [29] N.L.P. Hernandez, Bonon, J.O. Bahú, M.I.R. Barbosa, M.R.W. Maciel, R. Maciel Filho J. Mol. Catal. A: Chem. 426, 550-556 (2017)

30. [30] Z. Wu, H. Li, D. Tu Anal. Methods 8, 2581-2587 (2015)

31. [31] H. Omidvarborna, A. Kumar, D.S. Kim Fuel Process. Technol. 140, 113-118 (2015)

32. [32] S.E. Mahesh, A. Ramanathan, K.M.S. Begum, A. Narayanan Energy Convers. Manage. 91, 442-450 (2015)

33. [33] S.N. Rabelo, V.P. Ferraz, L.S. Oliveira, A.S. Franca IJESD 6, 964 (2015)

34. [34] C.L. Cunha, A.S. Luna, R.C. Oliveira, G.M. Xavier, M.L. Paredes, A.R. Torres Fuel 204, 185-194 (2017)

35. [35] A. Matwijczuk, D. Karcz, R. Walkowiak, A. Niewiadomy, S. Wybraniec, G. Karwasz, M. Gagos Przem Chem 95, 1894-1898 (2016)

36. [36] Matwijczuk, A., Karcz, D., Walkowiak, R., Furso, J., Gładyszewska, B. e., Wybraniec, S., Niewiadomy, A., Karwasz, G. P., Gagoś, M., J. Phys. Chem. A 121, 1402-1411 (2017)

37. [37] A. Matwijczuk, A. Górecki, D. Kamiński, B. Myśliwa-Kurdziel, L. Fiedor, A. Niewiadomy, G.P. Karwasz, M. Gagoś, M., J Fluoresc 25, 1867-1874 (2015)

38. [38] M. Gagoś, A. Matwijczuk, D. Kamiński, A. Niewiadomy, R. Kowalski, D.P. Karwasz J Fluoresc 21, 1-10 (2011)

39. [39] A.S. Luna, I.C. Lima, C.A. Henriques, L.R. de Araujo, W.F. da Rocha, J.V. da Silva Anal. Methods (2017)

40. [40] J. Zhou, Y. Xiong, Y. Gong, X. Liu Fuel 202, 23-28 (2017)
41. [41] I. Shancita, H. Masjuki, M. Kalam, S. Reham, S. Shahir Energy Fuels 30, 4790-4805 (2016) 